\title{
FANTASIA LEIGA PARA UM RIO SECO: UMA LEITURA POÉTICO-MUSICAL
}

\author{
Bina Friedman Maltz
}

RESUMO: Este artigo faz uma leitura poético-musical do poema narrativo orquestrado Fantasia leiga para um rio seco, de Elomar Figueira Mello. Musicalmente, analisa os cantos que o compõem com seqüências narrativomusicais da saga do catingueiro retirante em sua trágica caminhada para para a morte sabida, avaliando os recursos de instrumentação, voz, ritmo e melodia como responsáveis pela dramaticidade da composição. Literariamente, examina, de um lado, a organização métrica e sonora dos versos como procedimento que, em perfeita consonância com a música, instaura o veio dramático na letra, e a linguagem imagística em alguns deles como elemento que confere poeticidade ao texto; de outro, aponta para a leitura que faz da tradição oral sertaneja - ao recuperar a seca do Noventinha - e da tradição religiosa - ao apropriar-se do texto bíblico - , as duas vertentes que inspiram o imaginário do poema. Fantasia conjuga estética e semanticamente música e poesia, articula o diálogo entre o velho e $o$ novo, entre o sagrado e o profano e opera, via expedientes literários e musicais, a passagem do estrito viés da música regional para a dimensão universal.

PALAVRAS-CHAVE: música popular, poesia, literatura,tradição oral, tradição bíblica, dialogismo, polifonia, regionalismo, universalidade, tradição recriada.

Poema narrativo orquestrado, Fantasia leiga para um rio seco composição sertaneja de Elomar Figueira Mello, autor da letra e música, cantor e violonista - conta pela voz intimista e fortemente dramática de um cantor-narrador em primeira pessoa, no tempo presente, uma história acontecida que se incorporou à tradição oral do Nordeste - a seca do Noventinha, ou, como também ficou conhecida, a Fome do Noventinha, que devastou sete estados da região em 1890, deixando como nunca antes rastro igual de morte e destruição.

Universidade Federal do Rio Grade do Sul 
É essa tradição oral uma das vertentes que inspira o imaginário poético de Fantasia. A inspiração aqui nasce dos causos ouvidos pelo autor desde a infância na casa dos pais, que por sua vez ouviram dos seus, e estes dos seus, os relatos da saga do catingueiro retirante em sua solitária caminhada na esperança de alcançar a Mata-Cipó ou as plantações de cacau e fumo do sul da Bahia, onde, pelo que se sabia, ainda restava um pouco de vida.

Fantasia tinha no violão o seu instrumento original, mas certamente mostrou-se pobre para emprestar à peça toda a dramaticidade que o tema pedia. Daí talvez ter Elomar entregue o arranjo a Lindenbergue Cardoso, compositor erudito, que abriu o acorde do violão para orquestra sinfônica, à qual foram acrescentados um coral misto e um acordeon.

Embora a orquestra seja a sinfônica tradicional, a orquestração não é rica, majestosa, como a que caracteriza uma sinfônica. É discreta, cumprindo uma função de apoio: sublinha o tema do poema, dá eco à voz do solista e desenha o pano de fundo do quadro narrado - o do retirante da catinga do Rio Gavião, assolada por uma seca e por uma fome que chibateou e ceifou milhares de vidas catingueiras.

Fantasia inicia com a Abertura, só orquestrada, abrindo com dois ou três acordes de violão que se ampliam para a orquestra em dois episódios ${ }^{l}$ que se alternam e se justapõem com pequenas variações. O primeiro, sugerindo uma atmosfera pesada, dada principalmente pelas cordas, num ritmo arrastado e de sonoridade áspera, parece descrever a aridez e a devastação deixadas pelo Noventinha, o que cria uma imagem de morte e desolação, imagem que permeia todos os cantos e que domina toda a composição. O segundo, de sonoridade bem mais leve, mas de ritmo mais ágil, marcado por instrumentos de sopro, resulta na impressão, evidentemente subjetiva, do caminhar contínuo e solitário do catingueiro retirante sob um sol abrasante. Nada apoteótica esta abertura que, como tal, introduz o clima da obra.

À Abertura segue-se Incelença pra terra que o sol matou, em que o catingueiro descreve o quadro da seca como se a estivesse presenciando. E isso explica-se: o cantor ao cantar a seca do Noventinha está a cantar a seca que já se anuncia em 1980, ano da composição, e que ameaça novamente os sete estados do sertão. E o narrador sabe que mais um tempo apocalíptico virá.

\footnotetext{
1 O termo está empregado segunda a definição em BORBA, Tomás \& GRAÇA, Fernando Lopes. Op. Cit., v.1, p. 468: "nas formas clássicas, entende-se por episódio o desenvolvimento rigoroso que segue à exposição de temas. Nesse desenvolvimento, raras vezes intervêm novas idéias, as quais tirariam à composição a unidade precisa em toda a obra de arte. O episódio (ou divertimento, como também se lhe chama), deve fazer-se, em rigor, à custa dos próprios temas, alternando-se, sobrepondo-se, cromatizando-os, invertendo-os, modulando-os e decompondo-os à inventiva do compositor".
} 
Em Tirana ( $2^{\circ}$ canto), o catingueiro decide pela retirada e começa a narrar a sua lenta e penosa caminhada, levando a dor de uma saudade tirana: da terra, da mulher e do filho mortos. Decisão não só dolorosa como trágica: ele sabe que sai "prú vai-num-torna prá num voltá mais aqui/ in terra istranha e morrê longe do sertão", sabe que "todos qui fôro num voltaro tão nos ceus".

Em Parcela, o canto seguinte, o retirante se debate em conflito: culpa-se por estar "abaldonano as patra do sertão" mas quer uma chance de vida. Tenta aplacar sua consciência e a angústia da quase certeza do que Parcela vaticina: "do vai-num torna num se volta não".

$\mathrm{O} 4^{\circ}$ canto, Contra-Dança, é só orquestrado, e o último, Amarração, quase que exclusivamente orquestrado, é o epílogo da narrativa com a morte do catingueiro, sugerida na letra por apenas um refrão que se repete de quando em quando: "Cadê os pé do imbuzêro/ qui flora todo ano/ nas baxada e nas vereda mana mia/ cadê os pé d'imbu meu mano/ adeus pé dos imbuzêro". Moribundo, o retirante chega ao fim da jornada - a sonhada zona da Mata-Cipó. Só, exausto, de arrasto, "nú e cum fome quemano meus pé no chão", como diz Tirana, ele tomba. Como ele bem sabia, do "vai-num-torna num se volta não". Os que não foram morreram, mais "u'a ossada fulorano o chão" (Incelença) ressecado pelo "sol da má sorte/rei da tribusana", como dizem ainda os versos do mesmo canto.

O que a tradição do Noventinha prolongou foi a história desse homem que se ficasse morria e se fosse morria também. Foi a história do último animal que agonizava faminto e com sede, dos umbuzeiros queimados, do leito seco do Rio Gavião. Sol inclemente, solidão, morte, saudade, desolação e muita fé, como diz Incelença ("mais num há de sê nada/ na função dos bêsta/ purriba da festa/ pirigrina a fé") e tirana ("vejo o céu se abrino/ ela e o minino/ tão drumino/ na Santa Glora/ de Deus" - o retirante, afetado pelo sol abrasador, tem visões: vê por uma fissura no céu a mulher e o filho mortos sob a guarda de Deus) - é o que a tradição fixou e o que Fantasia reconta poeticamente.

A outra vertente que inspira a composição vem dos textos sagrados (veja-se em Incelença "a palavra vea", remissão às Escrituras) e faz-se à luz dos textos proféticos (veja-se no mesmo canto: "a palavra vea/ reza qui havéra/ de chegá um tempo/ só de perdedera"). É à essa luz - evidenciando uma cultura popular de profundo sentimento religioso que se funda no respeito à palavra sagrada, a palavra velha dos iluminados por Deus, como São João, o Apóstolo - que o narrador, a exemplo dos sete anjos, anuncia que é chegada a hora do acerto com Cristo, do Juízo Final. Os versos de Parcela mostram: "já vem vino sem demora/ c'as voiz dos truvão/ o Rei do Glora/ Rei da Glora/ muitos mili anjo in grande preparação/ nos alto ceus/ vem vino sobre essa Terra/ prá julgá os homes maus/ qui ofendêro a Deus/ oço o toco dos Rubin trobetêro/ atraiz dos veus". A apropriação é nítida:

"E vi sete anjos que estavam em pé diante de Deus e lhes foram dadas sete trombetas. 
E veio outro anjo, e parou diante do
altar, tendo um turíbulo de ouro, e lhe
foram dados muitos perfumes das orações de
todos os santos, para que os pusesse sobre
o altar de ouro, que estava ante o trono
de Deus. E subiu o fumo dos perfumes das
orações dos santos da mão do anjo diante
de Deus. E o anjo tomou o turíbulo e o
encheu de fogo do altar, e o lançou sobre
a terra, e logo se fizeram trovões, e
estrondos, e relâmpagos, e um grande
terremoto. Então os sete anjos, que tinham
as sete trombetas, se prepararam para as
fazer soar." (Apocalipse de S. João Apóstolo, cap. 8, vv. 2-6)

Daí, desse sentimento religioso, dessa crença nas antigas profecias e no determinismo divino, emanar do texto a resignação fatalista que responde pela tragicidade da trajetória do retirante em direção à morte. Neste particular, tem o texto outro claro referencial bíblico, inspirado no Livro de Jó. Varão de conduta irrepreensível, como narra o Antigo Testamento, Jó perde seus bens, filhos e saúde, mas não a devoção a Deus ou respeito pela Sua vontade:

"E um dia em que seus filhos e filhas estavam comendo e bebendo vinho em casa de seu irmão primogênito, veio ter com Jó um mensageiro, que lhe disse: Os bois lavraram, e as jumentas pastavam junto a eles, e vieram sobre eles de repente os sabeus, e levaram tudo, e passaram à espada os criados, e só eu escapei para te trazer a nova. E estando ainda este falando veio outro, e disse: Fogo de Deus caiu do céu, e ferindo as ovelhas, e aos pastores os consumiu, e escapei eu só para te trazer a nova. Ainda este falava, e eis que chegou outro, e disse: Os caldeus se dividiram em três esquadrões, e se lançaram sobre os camelos, e os levaram, e até passaram à espada os criados, e só eu escapei para te trazer a nova. Ainda este estava falando, e eis que entrou outro, e disse: Estando teus filhos e filhas comendo e bebendo vinho em casa de seu irmão mais velho, de repente se levantou um vento muito rijo da banda do deserto, e abalou os quatro cantos da casa, a qual caindo esmagou a teus filhos e morreram, e só eu escapei para te trazer a nova. Então 


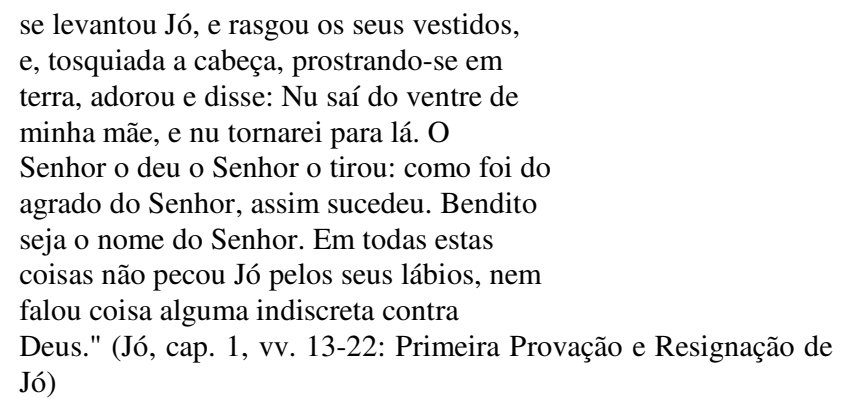

É, pois, a partir da tradição oral e dos textos bíblicos que Elomar, contando em versos esta página da saga de seu povo, garante a continuidade da tradição e da memória popular e religiosa sertanejas, cumprindo pela palavra poética, a palavra sagrada do versículo 3, cap. 1, do Livro de Joel (em que se narra uma terrível seca acompanhada por uma praga de gafanhotos): "Fazei sobre isto uma narração a vossos filhos, e vossos filhos a seus filhos, e os filhos destes à outra geração". Elomar perpetua, assim, a narrativa secular, passada de boca em boca, ouvida em criança.

Fantasia Leiga integra-se, desse modo, à linhagem da literatura popular nordestina, a da literatura bíblica, o que a faz transcender o estrito regionalismo, pelo qual respondem o violão, o acordeon, a recuperação do texto oral do Noventinha, o linguajar inculto e a prosódia sertanejos. O veio popular e regional da composição enriquece-se com a sinfônica e a leitura do Evangelho, ganhando musical e literariamente, dimensão universal.

A obra é inovadora e original desde o título. Fantasia, segundo dicionários especializados, é uma "peça musical em que o compositor, pondo de parte os aspectos formais da construção clássica, deixa simplesmente atuar a fantasia da sua imaginação" (LELLO UNIVERSAL, p 967), é uma "composição em que o autor se subtrai livremente às regras formais da construção clássica" (BORBA \& GRAÇA, p. 493-4), uma "peça instrumental não de forma prescrita, mas de livre exteriorização" (SINZIG, p. 253). Sendo essa a concepção da obra, justifica-se a Fantasia do título. E leiga porque profana e popular, conforme a definição do termo: "do povo, pelo povo. Que ou aquele que não tem ordens sacras. Laical" (LELLO UNIVERSAL, p. 44). São esses os elementos que marcam o estilo do poema da seca da catinga do rio Gavião, o rio seco que acaba o título.

Assim, Fantasia leiga para um rio seco anuncia uma peça formalmente livre, inventiva, de caráter narrativo-musical e laico. Responsáveis por tal natureza são as duas vertentes, onde se abebera o imaginário do poema, e o arranjo. De um lado, a tradição oral e o texto bíblico que, embora respeitado em seu pensamento sagrado, profana-se aos sair das Escrituras para incoporar-se à cultura regional nordestina; de outro, o arranjo, que, se introduz na música regional um tratamento altamente 
sofisticado com o recurso da sinfônica, caipiriza a orquestração ao acrescentar-lhe instrumentos populares.

Tome-se Incelença pra terra que o sol matou para uma análise mais detida. $\mathrm{O}$ canto é uma apropriação estilizada da excelência, cantiga de velório em uníssono, sem acompanhamento instrumental, cuja variação popular no Nordeste é incelença ${ }^{2}$

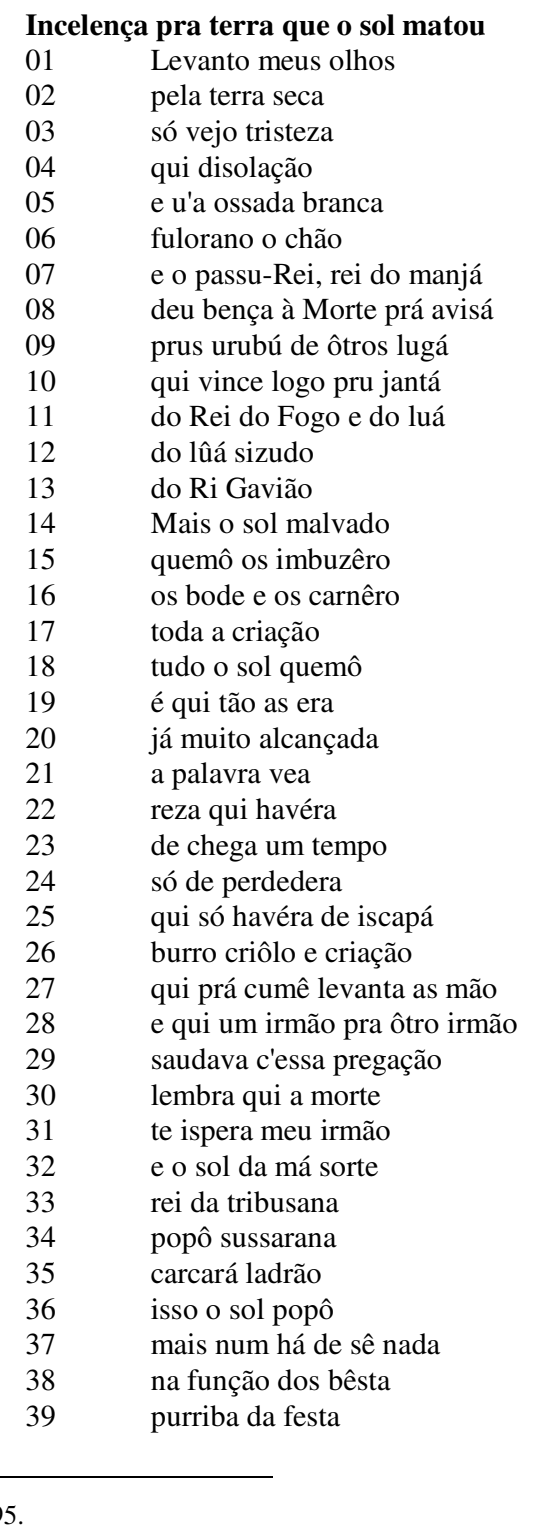




$\begin{array}{ll}40 & \text { pirigrina a fé } \\ 41 & \text { sei qui ainda resta } \\ 42 & \text { cururú-têtê } \\ 43 & \text { na minha casa hai um silenço } \\ 44 & \text { a tuia pura e o surrão penso } \\ 45 & \text { o meu cachorro amigo menso } \\ 46 & \text { deitô no chão ficô in silenço } \\ 47 & \text { e nunca mais se alevantô } \\ 48 & \text { inté os olhos-d'água } \\ 49 & \text { chorô qui secô } \\ 50 & \text { e o sol dessas mágua } \\ 51 & \text { quemô os imbuzêro } \\ 52 & \text { os bode e os carnêro } \\ 53 & \text { toda a criação } \\ 54 & \text { tudo o sol quemô } \\ 55 & \text { no Ri Gavião } \\ 56 & \text { tudo o sol quemô } \\ 57 & \text { toda a criação }\end{array}$

A voz baixíssima do cantor, versos brancos, à excessão dos 4 e 6 , e um violão chorando são recursos que imprimem o tom de lamento nos seis primeiros versos do canto, quando opera-se uma mudança de ritmo. Agora rígida, a métrica do $7^{\circ}$ ao $11^{\circ}$ versos, as rimas emparelhadas, todas em tônica aberta em maciça assonância, e a inflexão fortemente cadenciada do cantor e do violão são responsáveis pela reversão do lamento inicial, dolorido e desolado, em expressão enfática da agonia do catingueiro diante do quadro que vê.

Os versos 12 a 24 retomam a métrica dos seis primeiros, voz e violão voltam ao tom quase monocórdio e as rimas, num jogo de efeito poético, emparelham-se (versos 15 e 16; 21 e 22), alternam-se (versos 19 e 21; 22 e 24) e interpolam-se (versos 13 e 17; 14 e 20; 19 e 22), jogo quebrado por três versos brancos $(12,18$ e 23$)$ que também escapam ao sistema de oposição sonora das rimas (imbuzêro, carnêro, era, vea, havéra, perdedera). Os procedimentos formais constroem semanticamente o aflitivo tom de lamúria, próprio da excelência.

Rompe-se tal procedimento e o tom por ele imputado nos versos 25 a 29, quando entram coro e orquestra em uníssono e em ritmo rigorosamente marcado, apoiando a metrificação novamente rígida dos versos e a seqüência de rimas emparelhadas que, exceção feita ao verso 25 , jogando com a assonância, faz eco ao uníssono do arranjo enquanto reforça, pela compacta sonoridade da tônica fechada, a dramaticidade que os demais recursos da letra e música dão aos versos.

Do verso 30 ao 42 tem-se só voz e violão, numa interpretaçào outra vez plangente que modula lamento e indignação, e lamento e resignação. A indignação sente-se nos versos 32 a 35, quando a entoação cresce em volume e intensidade dramática, caindo no verso 36 para assumir, no 37, uma inflexão que sugere o sentimento resignado explícito no verso ("mais num há 
de sê nada"), resignação essa vinda da fé: "na função dos bêsta/ purriba da festa/ pirigrina a fé/ sei qui ainda resta/ cururú-têtê". A religiosidade, impregnada na cultura do catingueiro, é o único alento para a tristeza, a revolta e o desconsolo do sertanejo rodeado de morte, que ainda vê uma esperança no sapo grande e forte, o "cururu-têtê", que restou. Concorrem para esta impressão imagens poéticas construídas por metáforas alusivas ao sol em brasa em tempos de seca, como "o sol da má sorte/ rei da tribusana/ (...) carcará ladrão", que "quemô os imbuzêro/ os bode e os carnêro/ toda a criação".

Os versos aqui organizam-se sonoramente por rimas alternadas (versos 30 e 31; 39 e 41), emparelhadas (versos 33 e 34; 38, 39, 40, 41, estas em oposição de som aberto e fechado: bêsta, festa, fé, resta) e interpolada (versos 31 e 35), o que dá acabamento ao conjunto de recursos técnicos que traduz as múltiplas emoções vividas pelo narrador nesta passagem.

Sustentando os versos 43 a 47, entram novamente orquestra e coro, sempre em uníssono, voltando na letra o rigor métrico e a sonoridade também em uníssono, efeito alcançado pela absoluta assonância das rimas emparelhadas, unidade só quebrada pelo último verso, branco. Intensifica-se mais uma vez a dramaticidade, para o que concorrem a idéia de morte que passa de cada um dos quatro versos, a voz e a interpretação do cantor, o ritmo e a sinfônica, cuja presença, nesse e nos demais momentos, compacta semanticamente a imagem patética da catinga do Rio Gavião.

No último episódio (versos 48 a 57), cabe ao lamento dar fecho à Incelença. Voz, violão e orquestra, já sem o coral, acompanham em tom chorado os versos 48 a 54, sendo que nos 55, 56 e 57 permanecem apenas voz e violão, que vão morrendo até retomarem o tom plangente e pianíssimo dos primeiros versos. Fecha-se, desse modo, a estrutura circular deste canto, iniciado com a cantiga singela e triste do cantor e seu violão, em flagrante contraste com a solenidade, embora contida, do arranjo de orquestra e coro que, por lembrar um coral sacro, sustenta o clima de religiosidade que emana de toda a composição, como pede uma excelência.

$\mathrm{Na}$ letra, a metáfora e o jogo de palavras criam imagens poéticas nos versos 48 a 50 ("inté os olhos-d'água/ chorô qui secô/ e o sol dessas mágua") e as rimas, outra vez mais livres, mas sustentando um sistema sonoro, alternam-se (versos 48 e 50; 53, 55 e 57; 54 e 56), emparelham-se (versos 51 e 52) e interpolam-se (versos 49, 54 e 56) com predominância quase absoluta do timbre grave, o que emite, por efeito, uma imagem acústica de valor semântico, dando amparo à imagem sinistra da morte.

A aflitiva mesmice temática e a insistente repetitividade de ritmo, a sonoridade e a melodia recuperam em Incelença o canto de velório que chora e se despede de um morto - aqui metaforicamente ampliando sua significação para "os imbuzêro, os bode e os carnêro, toda criação" da catinga do Rio Gavião.

Incelença apropria-se de um texto oral da cultura popular religiosa do Nordeste, estabelecendo com ele um diálogo poético-musical. Enriquecido 
artisticamente com poesia e orquestração, o texto mantém, no entanto, seu tema e sentido primeiros; vale dizer, estiliza-o. Ao lê-lo recriadamente, faz-se um duplo, um texto plural. Ao evocá-lo, aproxima-se dele prolongando-o, o que lhe garante a permanência. Como um todo, Fantasia leiga para um rio seco define-se como um texto polifônico ${ }^{3}$. Adquire a obra um significado singular: o de estar em relação simultânea com os textos, seus predecessores, saídos das duas vertentes referidas, tornando-os um corpo vivo no presente e tornando-se ela mesma um corpo vivo do acervo já existente. Nisso consiste a harmonia entre o velho e o novo, o que assegura a continuidade, fazendo a tradição.

Parece ser este o valor de Fantasia em meio à redundante rotina temática e musical das canções sertanejas, hoje feitas modismo urbano e rendoso achado da indústria cultural. Não tivesse esse valor, ainda teria Fantasia o mérito, graças a concentrar em Elomar o letrista e o compositor, de conjugar estética e semanticamente poesia e música, que se faz, para Wisnik, justamente da "descoberta recíproca entre letra e melodia, tensão flutuante surfando sobre as ondas da harmonia" (WINSIK, p. 8).

\section{BIBLIOGRAFIA}

BAKHTIN, Mikhail. Problemas da poética de Dostoiévski. Rio de Janeiro, Forense-Universitária, 1981.

. Marxismo e folosofia da linguagem. São Paulo, Hucitec, 1986.

BÍBLIA SAGRADA. Rio de Janeiro, Barsa, 1969. Tradução Padre Antônio Pereira de Figueiredo, notas e dicionário prático por Mons. José Alberto L. de Castro Pinto.

BORBA, Tomás; GRAÇA, Fernando Lopes. Dicionário da música. Lisboa, Cosmos, 2v, 1962.

CARVALHO, Gilberto. Chico Buarque: análise poético-musical. Rio de Janeiro, Codecri, 1982.

ELIOT, T. S. Tradition and individual talent. In: Selected prose of T. S. Eliot. London, Faber and Faber, 1975.

FERREIRA, Aurélio Buarque de Holanda. Novo dicionário da língua portuguesa. Rio de Janeiro, Nova Fronteira. 1975.

\footnotetext{
3 O termo está empregado no sentido que lhe dá Bakhtin ao analisar o romance de Dostoiévski, que, por conter a voz do "outro", seria em oposição ao monologismo, um romance de tratamento dialógico, como está em Problemas da poética de Dostoiévski, capítulo 2 (A personagem e seu enfoque pelo autor na obra de Dostoiévski, p.39-64). A idéia desta voz do "outro" no discurso de umtexto está desenvolvida também em Marxismo e filosofia da linguagem capítulo 9 (O discurso de outrem, p.144-54).
} 
JENNY, Laurent. A estratégia da forma. In: INTERTEXTUALIDADES. Coimbra, Almedina, 1979. (Poétique: Revista de teoria e análise literárias, v. 27).

KRISTEVA, Julia. Introdução à semanálise. São Paulo, Perspectiva, 1974. (Col. Debates: Semiótica).

LELLO UNIVERSAL: DiCIONÁRIO ENCICLOPÉDICO LUSO-BRASILEIRO. Porto, Lello \& Irmãos, s.d. 4v.

PAZ, Octávio. O poema. In: O arco e a lira. Rio de Janeiro, Nova Fronteira, 1982.

SANT'ANNA, Affonso Romano de. Paródia, paráfrase \& Cia. São Paulo, Ática, 1985. (Série Princípios, 1).

SINZIG, Frei Pedro. Dicionário musical. Rio de Janeiro, Kosmos, 1946.

TYNIANOV, Iuri. Da evolução literária. In: EIKENBAUM, B. Teoria da literatura: formalistas russos. Org. de Dionisio de Oliveira Toledo. 4. ed. Porto Alegre, Globo, 1978.

WISNIK, José Miguel. Letras e músicas e acordes cifrados. In: CHEDIAK, Almir. Songbook. Rio de Janeiro, Lumiar, v. 2, 1988.

\section{DISCOGRAFIA}

ELOMAR. Fantasia leiga para um rio seco. Salvador, Auditório do Centro de Convenções da Bahia, dezembro de 1980. 